\title{
An Improved V-Shaped Interior Permanent Magnet Rotor Topology with Inward-Extended Bridges for Reduced Torque Ripple
}

\author{
Peng Gao ${ }^{1,2}$, Xibin Sun ${ }^{1}$, David Gerada ${ }^{3 *}$, Chris Gerada ${ }^{3}$, Xiaoyuan Wang ${ }^{1}$ \\ ${ }^{1}$ School of Electrical and Information Engineering, Tianjin University, Tianjin, China \\ ${ }^{2}$ Xi'an Micromotor Research Institute, Xi'an, China \\ ${ }^{3}$ Department of Electrical and Electronics Engineering, University of Nottingham, Nottingham, UK \\ *david.gerada@nottingham.ac.uk
}

\begin{abstract}
Interior permanent magnet synchronous machines (IPMSMs) with V-shaped permanent magnet (PM) rotors are widely used as traction motors in electric vehicles (EVs) because of their high torque density and high efficiency. However, the V-shape IPMSMs have the disadvantages of inevitable torque ripple due to the non-sinusoidal air-gap flux density distribution and the utilization of the reluctance torque. In this paper, with the aim of improving the torque ripple characteristics, a modified V-shaped IPMSM rotor configuration with bridges extended inwards towards the pole center is proposed to generate a more sinusoidal air-gap flux density waveform. The proposed topology, referred to as 'Type $C^{\prime}$ within this paper, is compared to baseline rotor configuration references, namely 'Type A' which is a conventional V-shaped PM rotor, as well as 'Type B' which is a related configuration with a mechanically non-uniform airgap. Analysis results show that the rotor 'Type C' exhibits significant advantages in term of reducing cogging torque, torque ripple and radial force, without incurring additional airgap friction losses. Finally, a prototype of the IPMSM with the proposed rotor configuration is manufactured and tested, verifying experimentally the predicted benefits.
\end{abstract}

\section{Introduction}

With the increasingly stringent emissions requirements and with many countries setting dates eliminating sales of ICE-based vehicles, research and development on electric vehicles (EVs) is at an all time high. The electrical machine is at the heart of EV architectures, hence the current focus is on increasing its power density or cost performance to targets set by national bodies such as the DoE in the USA or the APC in the UK $[1,2]$. The interior permanent magnet synchronous machine (IPMSM) is an excellent candidate for EV propulsion, and infact many automotive traction machines adopt this topology [3, 4]. Differently from the surface-mounted permanent magnet synchronous motors, there is asymmetry of the reluctance between $d$-axis and $q$-axis, which saliency can be used to produce reluctance torque in addition to the magnet torque, thus improving the efficiency. In addition, the IPMSMs provide more rotor robustness as magnets are embedded in the rotor laminations, hence no additional retention sleeving is required.

Various IPMSM technologies have been studied in literature. In [3], the V-shape, the U-shape, the spoke-type and the tangential type IPMSMs are compared. The spoke-type motor has the widest constant power speed range (CPSR) and the lowest average output torque. On the contrary, the tangential-type motor has the highest average output torque and the worst CPSR. The V-shape motor has good average output torque and lower torque ripple. In [4], the saliencies of three IPMSMs with the flat-shape, V-shape, and U-shape rotor topologies are investigated considering the magnetic cross-coupling effect. The V-shaped PM motor has the highest saliency ratio. In [5], the demagnetization characteristics of PMs in four IPMSMs with the flat-shape, the V-shape, the flux concentrated, and the flux concentrated- $\mathrm{V}$ rotor topologies considering the nonlinearity of PMs are investigated. It is found that the PMs of flat-shape and V-shape rotors have better demagnetization characteristics due to the reduced armature reaction influence on them. Ref. [6] also performs a study on the demagnetization characteristics of PMs, and the results show that the PMs in the flat-shaped PM rotor are much easier to be demagnetized under the maximum torque operation with respect to the $\mathrm{V}$-shaped magnets. In summary, considering the many important factors in play, the IPMSM with $\mathrm{V}$-shape rotor seems to be one of the better compromises amongst the other IPM configurations, hence its more widespread adoption in commercial HEVs/EVs.

Despite the aforementioned merits of the IPMSM with V-shape rotor, issues still exist, setting up the scope for further research investigations. It has the disadvantages of inevitable torque ripple due to (i) the non-sinusoidal air-gap flux density and (ii) the utilization of the reluctance torque [7]. As the torque ripple affects the vibration and noise (and hence driveability), it should be reduced [8]. There are various V-shaped PM rotor variables which influence the torque characteristics of IPMSMs, and several methods have been shown to improve the torque characteristics of the V-shape IPMSM. In [9] and [10], the skewed slot stator is adopted in order to reduce the cogging torque and the torque ripple while in [11][12][13], the step-skewed rotor is used to achieve similar effects. These are infact widely adopted 
traditional methods, which lead to the increase of the manufacturing cost/time and the decrease of the average output torque. In order to reduce the torque ripple without detriment to the average output torque, an asymmetrical $\mathrm{V}$-shape rotor configuration of an IPMSM is presented in [14]. This is proven to be an effective way to reduce the torque ripple albeit there exists a limitation to single rotation direction (i.e. unidirectional benefit). Based on the research work in [14], a novel asymmetrical V-shape rotor is proposed in [15]. The novel rotor structure exhibits satisfactory torque characteristics, without the limitation to rotation direction. Another kind of asymmetrical rotor by designing a non-uniform air-gap is studied in [16] and [17], with the sinusoidal air-gap flux density waveform achieved by adjusting the non-uniform air-gap length. A similar rotor structure is also studied in [18], which proposes an asymmetrical rotor with non-uniform distribution of holes. In addition, the bridges and ribs of $\mathrm{V}$-shape rotor are studied in [19][20][21], where it is shown that these can be optimized to maximize the fundamental air-gap flux density and minimize its total harmonic distortion (THD).

This work presents a modified V-shaped PM rotor topology which reduces the torque-ripple by extending the bridges further inwards towards the pole center. This paper is organized as follows. Section 2 describes the origins of torque ripple together with the prior-art concept of mechanical pole shaping as a means to reduce it. Based on the aforementioned, the proposed concept 'Type $C$ ' is introduced as an alternative way of achieving similar performance benefits with the key advantage of having a uniform physical airgap. The electromagnetic performances of the topology are investigated in Section 3, while Section 4 verifies the mechanical suitability. The prototype with the proposed rotor concept is built and experimentally validated in Section 5, and finally in Section 6 conclusions from this research are discussed.

\section{IPMSM for EV traction}

The electric motor is at the heart of the electric propulsion system in EV, and thus it has to satisfy multiple important requirements such as high output torque at low speeds, high power output at high speeds, and high efficiencies within a wide speed range. Besides, the cogging torque and torque ripple should be reduced, because these can produce mechanical vibrations and acoustic noise, thus degrading the performance of IPMSM drives, especially at low-speed operations.

Mathematically the cogging torque $T_{c o g}$ of this kind of machine is described as part of the magnetic torque, and can be expressed as :

$$
T_{c o g}=-\frac{1}{2} \Phi^{2} \frac{d R}{d \theta}
$$

where $\Phi$ is the magnet flux crossing the air gap, $R$ is the total reluctance through the flux paths, and $\theta$ is the rotor angle. It is clear that if the reluctance $R$ does not vary as the rotor rotates, then the cogging torque $T_{\operatorname{cog}}$ is zero. From this point of view, the cogging torque can be improved by changing the $\mathrm{V}$-shape rotor structure variables which affect the reluctance $R$.
In terms of torque ripple, a slight mismatch between the back electromotive force (EMF) of the machine and the current often produces torque ripple. As the windings of the IPMSM are excited with three-phase sinusoidal currents, it is crucial to obtain the sinusoidal back EMF waveform as well as the sinusoidal air-gap flux density. Thus it is important to consider the air-gap flux density $B_{g}$, which can be expressed as :

$$
\begin{gathered}
B_{g}=\frac{\Phi_{g}}{A_{g}}=\frac{\mu_{0} F_{g}}{l_{g}} \\
\Phi_{g}=\frac{F_{g}}{R_{g}}
\end{gathered}
$$

where $F_{g}$ is the air gap magnetomotive force, $R_{g}$ is the air gap reluctance, $A_{g}$ is the cross sectional area of the air gap, $\mu_{0}$ is the permeability of vacuum, and $l_{g}$ is the air-gap equivalent length.

The range of $\theta$ varies from $-90^{\circ}$ to $90^{\circ}$ in the electrical angle, then (3) can be expressed as a periodic function:

$$
B_{g}=B_{\max } \cos \theta=\frac{\mu_{0} F_{g}}{l_{g}(\theta)}
$$

where $B_{\max }$ is the maximum air-gap flux density.

According to (4), in order to obtain a sinusoidal air-gap flux density distribution, $B_{g}$ is maximum at the $d$-axis position, when $\theta$ is equal to zero. Moreover under the ideal condition, the air-gap flux density varies sinusoidally with the change of $\theta$. Then the air-gap equivalent length $l_{g}$ is a function of $\theta$.

From the foregoing discussion, based on the principle of generating sinusoidal air-gap flux density waveform and cogging torque, an effective method to reduce both the cogging torque and torque ripple is by using the $\mathrm{V}$-shaped PM rotor structures which have variable air-gap equivalent length.

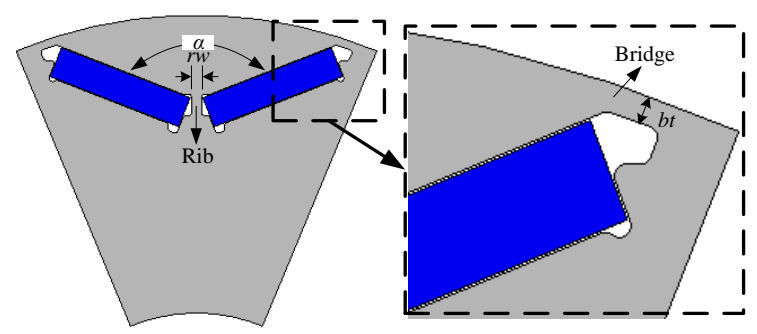

(a)

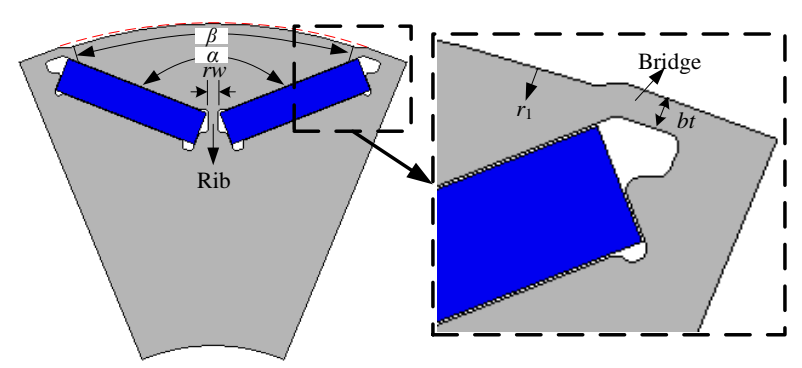

(b) 


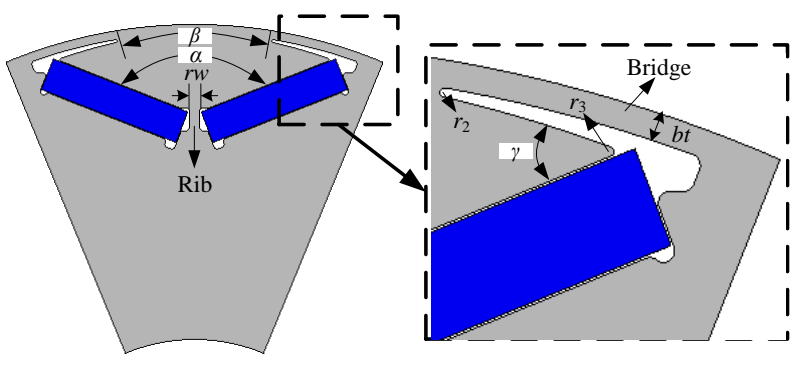

(c)

Fig. 1. Rotor structures. (a) Type A. (b) Type B. (c) Type C.

Fig. 1(a) shows the conventional rotor structure, hereafter referred to as 'Type A'. Rotor 'Type B', shown in Fig. 1(b) achieves a more sinusoidal airgap flux density distribution by mechanically shaping the rotor surface, resulting in a non-uniform mechanical airgap, as in [16], [18], while rotor 'Type $C^{\prime}$ achieves a similar effect, but rather than by mechanical pole shaping this is done through the use of the elongated bridge as evident from Fig. 1(c).

The studied V-shaped PM IPMSM is used as a traction motor in EVs, and the specifications of the motor are listed in Table 1. Based on the specifications, the three rotor types are developed and analyzed. The following conditions are satisfied in order to compare the merits and demerits of the three rotors in Fig.1: 1) the stator core, winding and shaft are identical; 2) the same amount and shape of PM is utilized; 3) the width of the bridge and rib, and $\alpha$ of the three IPMSMs are of the same value. The detailed values related to the magnetic bridge are listed in Table 2 .

Table 1 Specifications of machine

\begin{tabular}{|c|c|c|}
\hline Parameters & Unit & Value \\
\hline Rated Power & $\mathrm{kW}$ & 35 \\
\hline DC Voltage & $\mathrm{V}$ & 320 \\
\hline Maximum Current & $\mathrm{A}$ & 475 \\
\hline Rated Torque & N.m & 84 \\
\hline Maximum Torque & N.m & 255 \\
\hline Rated Speed & $\mathrm{r} / \mathrm{min}$ & 4000 \\
\hline Maximum Speed & $\mathrm{r} / \mathrm{min}$ & 12000 \\
\hline Number of Slots/Poles & & $48 / 8$ \\
\hline Stator outer/inner diameter & $\mathrm{mm}$ & $220 / 136.4$ \\
\hline Rotor outer/inner diameter & $\mathrm{mm}$ & $135 / 40$ \\
\hline Slot depth/ top width & $\mathrm{mm}$ & $27.6 / 3.4$ \\
\hline Slot opening width & $\mathrm{mm}$ & 2 \\
\hline Slot bottom radius & $\mathrm{mm}$ & 3.2 \\
\hline PM thickness & $\mathrm{mm}$ & 20 \\
\hline PM width & $\mathrm{mm}$ & 4.5 \\
\hline Stack & $\mathrm{mm}$ & 110 \\
\hline Air-gap length & $\mathrm{mm}$ & 0.7 \\
\hline Coil per Phase & turn & 16 \\
\hline Strand diameter & $\mathrm{mm}$ & 0.75 \\
\hline Number of strand in hand & - & 7 \\
\hline
\end{tabular}

In general, IPMSMs can be analyzed under the synchronous frame, as the stator winding are energized by $d$ - and $q$-axis currents respectively. The motor performance can be expressed by the $d$ - and $q$-axis inductances. However, the actual value of the inductances, varies nonlinearly due to the magnetic saturation, hence the finite element method (FEM) is used to calculate the performance for the IPMSM in this paper.

Table 2 Values of magnetic bridge

\begin{tabular}{cccc}
\hline \hline Parameters & Type A & Type B & Type C \\
\hline$\alpha /\left(^{\circ}\right)$ & & 137 & \\
$r w /(\mathrm{mm})$ & & 1.2 & \\
$b t /(\mathrm{mm})$ & & 1.2 & \\
$\beta /\left(^{\circ}\right)$ & - & 33 & 18 \\
$\gamma /\left(^{\circ}\right)$ & - & - & 37 \\
$r_{1}(\mathrm{Center}) /(\mathrm{mm})$ & - & $60(0,8.3)$ & - \\
$r_{2} /(\mathrm{mm})$ & - & - & 0.25 \\
$r_{3} /(\mathrm{mm})$ & - & - & 0.25 \\
\hline \hline
\end{tabular}

\section{Electromagnetic performance comparison}

\subsection{No-load characteristics}

The no-load flux density distributions of the three IPMSMs are shown in Fig. 2. As can be seen, the three motors have the same flux density at the ribs. The flux density distribution within the bridge of the proposed rotor 'Type $C^{\prime}$ is significantly different to the others. Along this elongated bridge the iron is saturated, with the level of saturation varying from $2.12 \mathrm{~T}$ down to $2.04 \mathrm{~T}$. In other words the varying airgap affect is obtained through the magnetic design rather than the physical pole shaping.

The air-gap flux density waveforms of the three motors are shown in Fig. 3. The fundamental component of air-gap flux density $B$ and the THD of the three motors are shown in Table 3. For the motor with the rotor 'Type $\mathrm{A}^{\prime}$, the distribution of air-gap flux density is lower and more distorted. The air-gap flux density distribution of the motor with the rotor 'Type $\mathrm{B}^{\prime}$ is more sinusoidal than that of the motor with the rotor 'Type A'. Infact the rotor structure with non-uniform air-gap formed by shaping the rotor polar surface is an effective measure to improve the air-gap flux density distribution. The motor with the rotor 'Type $C^{\prime}$ has the best air-gap flux density distribution with the largest fundamental amplitude and the smallest THD. The reason is that the leakage flux is reduced and more flux is concentrated along the $d$-axis of the rotor.
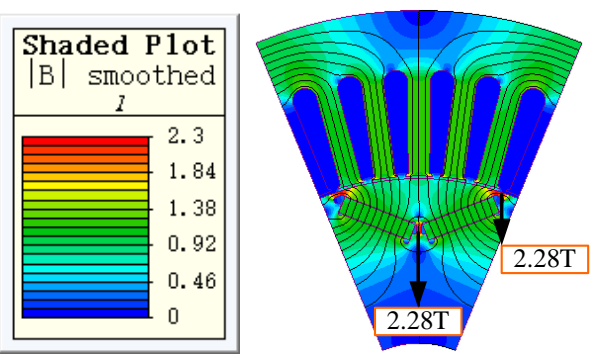

(a) 


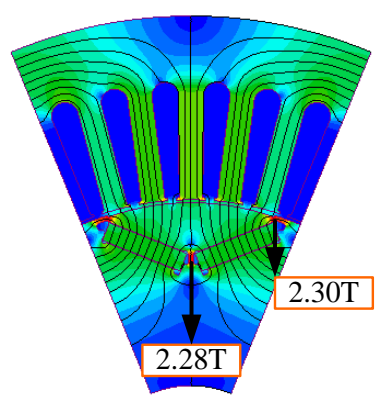

(b)

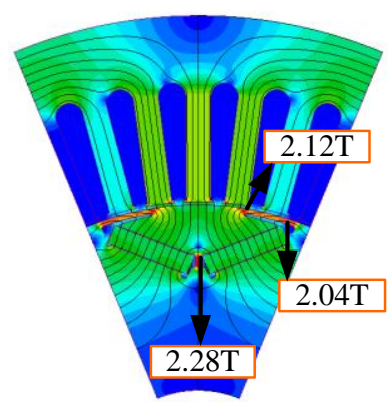

(c)
Fig.2. No-load flux density distributions of the three IPMSMS. (a) Type A. (b) Type B. (c) Type C.

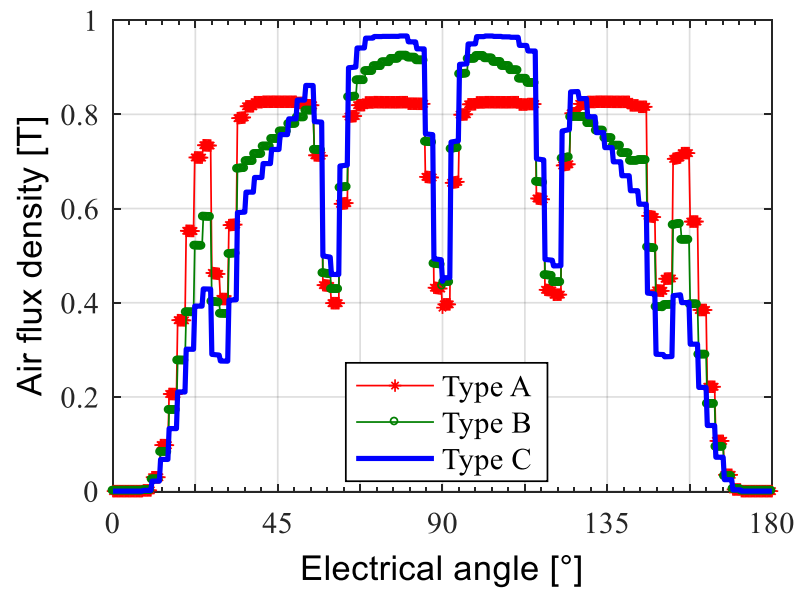

Fig.3 Air-gap flux density results comparison by FEA

Table 3 Fundamental air-gap flux density $B$ and THD

\begin{tabular}{cccc}
\hline \hline Parameters & Type A & Type B & Type C \\
\hline$B(\mathrm{~T})$ & 0.877 & 0.883 & 0.894 \\
THD $(\%)$ & 28.88 & 21.12 & 20.36 \\
\hline \hline
\end{tabular}

motors. Similarly comparing with the motor with rotor 'Type $\mathrm{A}^{\prime}$, the cogging torque is reduced by $39.59 \%$ with rotor 'Type B' and by $73.52 \%$ with rotor 'Type $\mathrm{C}$ '.

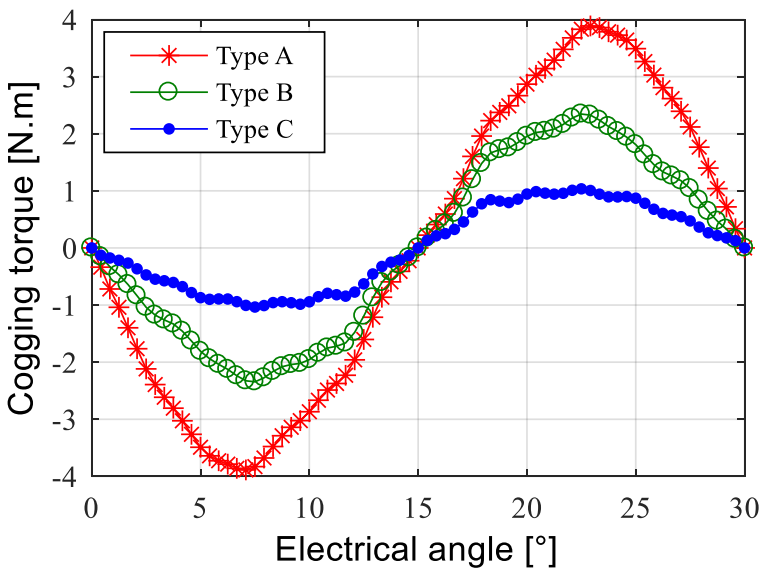

Fig.4 Cogging torque results comparison

Consequently, the utilization of the proposed rotor 'Type C', as with the case of the 'Type B', can effectively obtain a more sinusoidal distribution of the air-gap flux density, which translates to significantly positive effects on reducing the cogging torque.

\subsection{Load characteristics}

The electromagnetic properties of an IPMSM at the rated working point are the good criterion to evaluate their performance. The rated power and the rated speed of the IPMSM studied in this paper are $35 \mathrm{~kW}$ and $4000 \mathrm{r} / \mathrm{min}$, respectively, as per Table 1 .

To comprehensively compare the difference of the three motors, the maximum torque per ampere (MTPA) control strategy and the $i_{\mathrm{d}}=0$ control strategy are considered respectively in this section. Then the electromagnetic properties of the three motors at the rated working point are

Table 4 Comparison of electromagnetic properties at the rated working point between MTPA and $i_{\mathrm{d}}=0$ control method

\section{Parameters}

Power $(\mathrm{kW})$

Speed (r/min)

Current (A)

Advance angle $\left(^{\circ}\right)$

Voltage (V)

EMF (V)

Power factor

Efficiency (\%)

Winding loss $(\mathrm{kW})$

Stator iron loss $(\mathrm{kW})$

Rotor iron loss $(\mathrm{kW})$

Type A
35
4000
196
0
174
113
0.627
94.11
0.666
0.484
0.039

The cogging torque waveforms of the three motors are shown in Fig. 4. It can be seen that the cogging torque of motor with the rotor 'Type $\mathrm{A}$ ' is the highest among the three calculated by FEM, and the results are shown in Table 4. It can be seen that the currents of motors with rotor Type $\mathrm{C}$ and Type $\mathrm{B}$ are smaller than that of the motor with rotor 
Type A under the $i_{d}=0$ control strategy due to their higher back EMF and higher power factor. When using the MTPA control strategy, the currents of the three motors are reduced significantly due to the inherent reluctance of the topology. As the currents required to produce the rated power get smaller, the efficiency and power factors increase correspondingly. The currents of the motors with the physical airgap shaping 'Type B', and with inward-extended

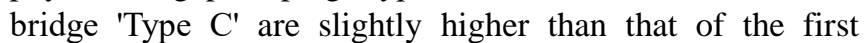
(conventional) one, which indicates some loss of reluctance torque. Correspondingly, their optimal advance angles are smaller at the rated working point. The reluctance torque of the three motors (Types A, B, C) are calculated, as 22.52 $\mathrm{Nm}$ (26.93\% of the rated torque), $21.35 \mathrm{Nm}$ (25.54\% of the rated torque), and $18.17 \mathrm{Nm}$ (21.73\% of the rated torque), respectively. Less reluctance torque is produced when rotor 'Type B' or rotor 'Type $\mathrm{C}$ ' is adopted. To delve into this point further, their inductances at different currents are calculated, and shown in Fig. 5.

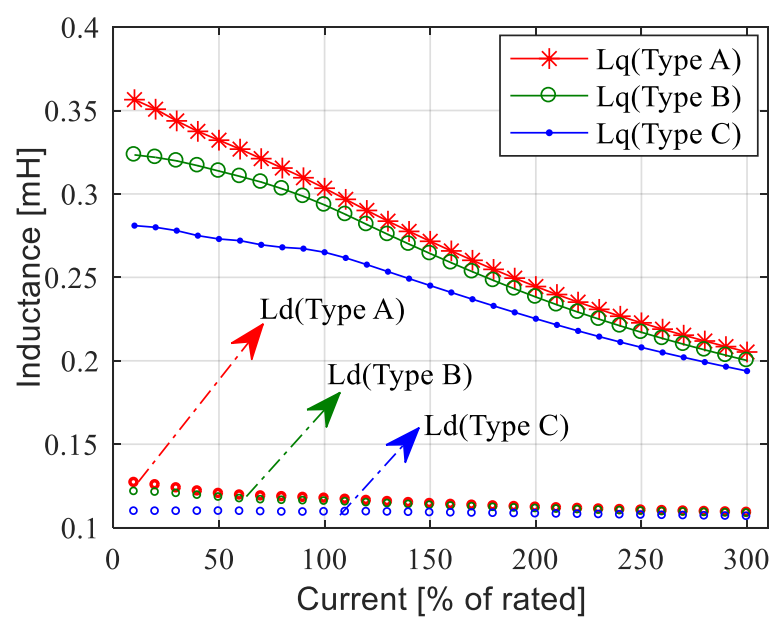

(a)

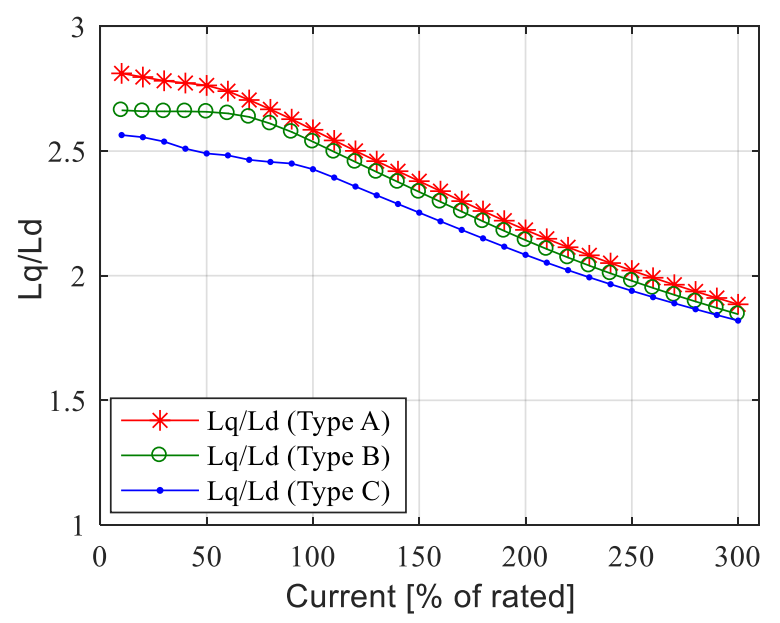

(b)

Fig.5 Inductances results comparison by FEA. (a) Inductance. (b) The ratio of $L_{q}$ to $L_{d}$

As shown in Fig. 5, the $q$-axis inductance $\left(L_{q}\right)$ and the ratio of $q$-axis inductance to $d$-axis inductance $\left(L_{q} / L_{d}\right)$ of the three motors all reduce with the current due to the saturation effect, albeit the variations of $L_{d}$ are less affected by the current. The motors with rotor 'Type B' or 'Type $\mathrm{C}^{\text {' have }}$ smaller $L_{q}$ or $L_{q} / L_{d}$ in the entire range of current. The reluctance torque not only depends on $L_{d}$ but also on the ratio $L_{q} / L_{d}$. From the foregoing discussion and analysis less reluctance torque is produced when rotor 'Type $\mathrm{B}^{\prime}$ or rotor 'Type $C^{\prime}$ is adopted in the IPMSMs.

The waveforms of torque of the three motors at the rated condition are shown in Fig. 6. They achieve similar average torque, however, the motor with rotor 'Type $\mathrm{A}$ ' has the highest torque ripple and the motor with rotor 'Type $\mathrm{C}^{\prime}$ has the lowest on-load torque ripple. Their torque ripples are $33.75 \%, 25.51 \%$ and $19.98 \%$, for rotor Types A, B, and C, respectively.

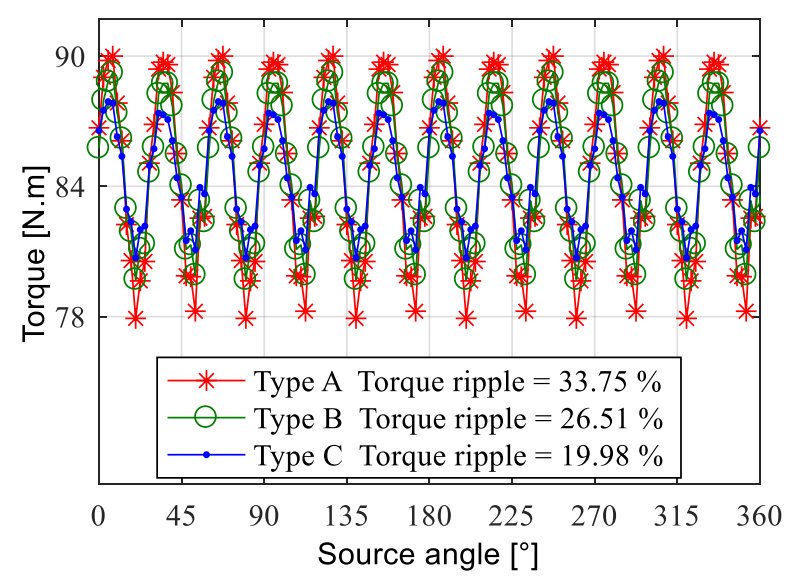

Fig.6 Torque ripple results comparison by $\mathrm{FEA}$.
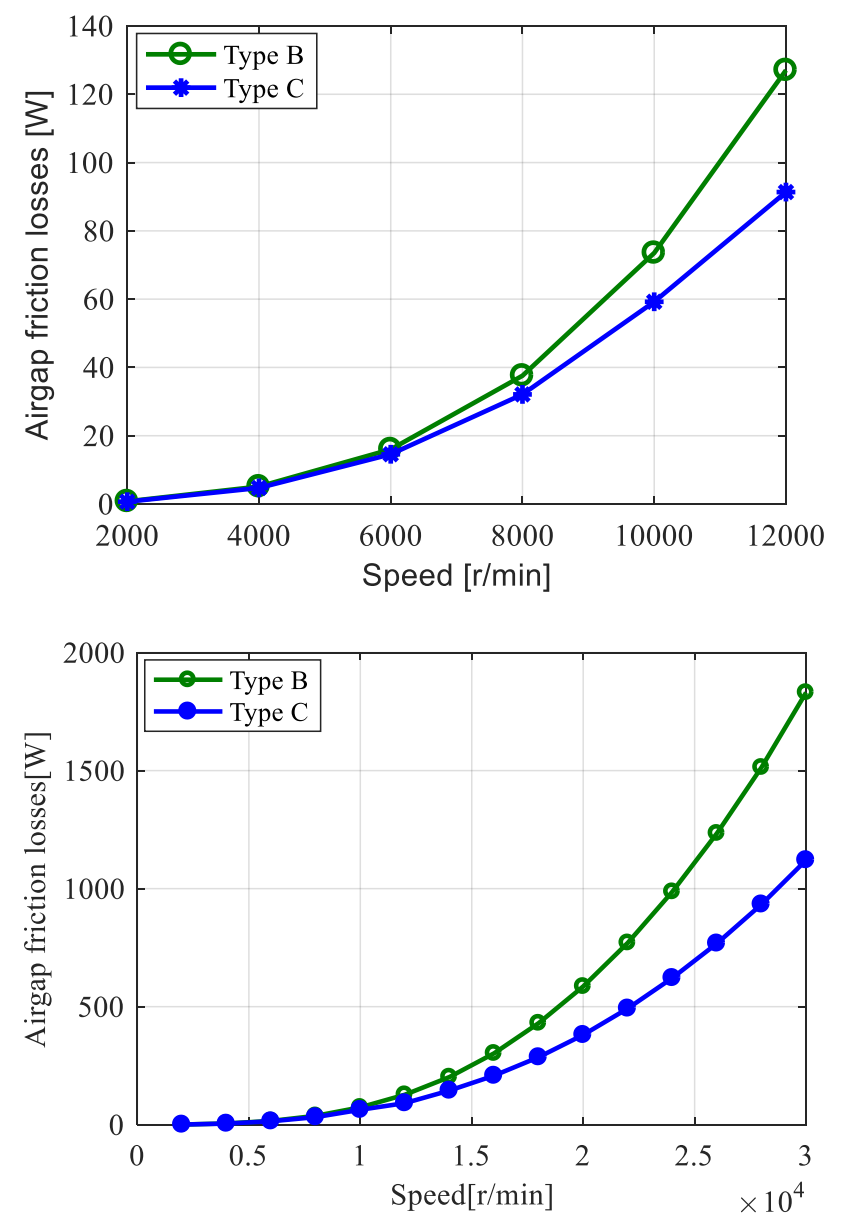

Fig.7 Airgap friction losses results comparison by FEA. 
The airgap friction losses of the IPMSM with the non-uniform airgap (rotor Type B) and the uniform airgap (rotor Type C) are calculated by FEA without considering cooling methods, as shown in Fig. 7. The airgap friction losses increase with increasing rotor speed. More airgap friction losses are produced when rotor 'Type B' is adopted. It is predictable that the airgap friction losses of the IPMSM with rotor 'Type B' will be significantly increased due to the non-uniform airgap and high rotational speeds under some cooling conditions such as the rotor ventilation cooling and the oil-spray cooling.

The traction motors are required to have an ability to operate within a wide range of speed efficiently. In EVs this is even more important, as efficiency is directly linked to the driving range and hence also linked to the overall customer acceptance. Under the MTPA control strategy, the steady-state efficiency characteristics of the three motors with a DC bus voltage of $320 \mathrm{~V}$ are calculated. Table 5 shows the statistics of the efficiencies of the three motors. The maximum efficiencies of the three motors are almost the same. Efficiencies above $80 \%$ of the three motors are spread over a large area of the operation region. The motor with rotor 'Type $\mathrm{A}^{\prime}$ has a slightly larger area of the operation efficiencies above $95 \%$, however, the motor with rotor 'Type $C^{\prime}$ has larger area of the operation efficiencies above $80 \%$, $85 \%$ and $90 \%$. As EV motors are operating most of the time across fairly wide power-speed ranges (contrary to say those in HEVs), it is likely that rotor 'Type $\mathrm{C}$ ' would give more driving range out of a single battery charge, but this conclusion would necessitate further vehicle-level analysis considering motor residency points over the applicable driving cycle [22].

Table 5 Motors statistical efficiencies

\begin{tabular}{cccc}
\hline \hline Parameters & Type A & Type B & Type C \\
\hline Max.efficiency (\%) & 95.78 & 95.75 & 95.73 \\
$>95 \%$ area & 20.63 & 20.30 & 20.02 \\
$>90 \%$ area & 56.73 & 56.87 & 58.59 \\
$>85 \%$ area & 73.42 & 73.87 & 76.42 \\
$>80 \%$ area & 84.12 & 84.25 & 85.45 \\
\hline \hline
\end{tabular}

\section{Radial force and mechanical stress comparison}

\subsection{Radial force analysis}

Due to the demanding requirements by industry for a comfortable passenger environment, the vibration and noise of traction motors require careful consideration. The vibration and noise in IPMSMs can be classified into three main areas based on its source: (i) electromagnetic, (ii) aerodynamic and (iii) mechanical [23-25]. Electromagnetic source is the dominating one in low- to medium-power rated machines [26]. Cogging torque, torque ripple, and radial force $F_{r}$ are the main electromagnetic sources of noise and vibration. $F_{r}$ is the normal component of the magnetic force, which is caused by the interaction between the rotor PMs and the stator teeth. A simple way to predict the noise and vibration of IPMSMs is by analyzing the radial force.

The FEA of IPMSMs with the three different rotor structures is carried out, from which $F_{r}$ is deduced, consisting of different time harmonics which are analyzed using a Fourier series, the results of which are shown in Fig.8. From the simulation results, it can be seen that not only the time harmonics, but also the spatial harmonics of radial force can be attenuated by the proposed rotor structures 'Type C'.

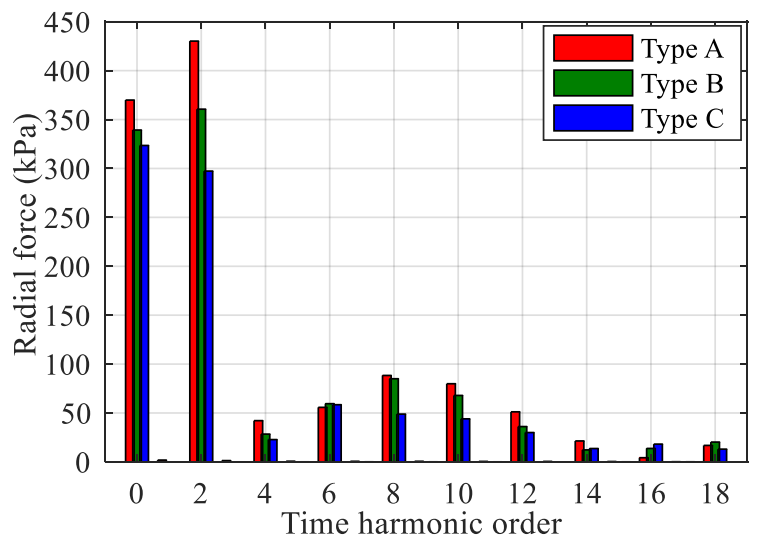

(a)

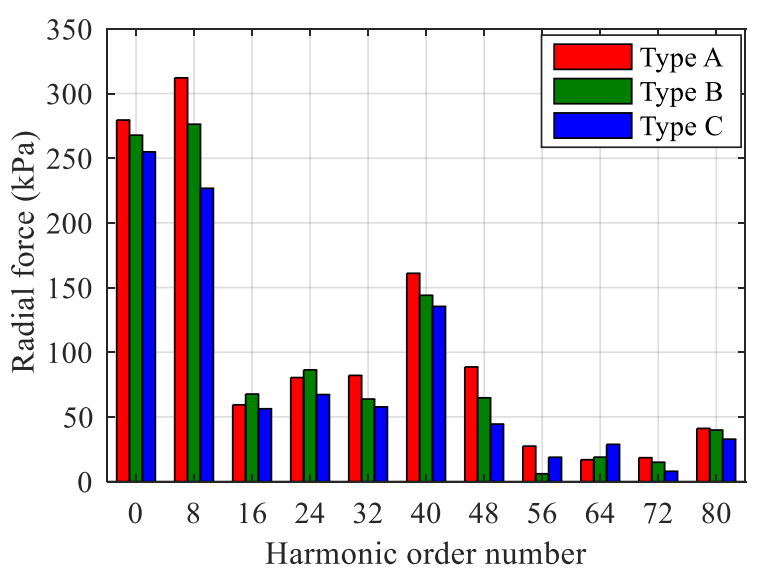

(b)

Fig. 8 Fourier decomposition of radial forces of IPMSMs with different rotors at rated state. (a) Radial force of one point. (b) Spatial distribution of radial force of one tooth surface

\subsection{Mechanical stress analysis}

A crucial issue of the $\mathrm{V}$-shape rotor design is that, the bridges and ribs should have sufficient mechanical strength to resist the high centrifugal force, particularly at the maximum speed. The materials M270-35A and N38UH are used for the laminations and PM, respectively, as a compromise between cost and performance. Their mechanical properties are shown in Table 6. Mechanical FEA is performed on the rotor assembly. Fig. 9 shows the von-Mises stresses of the three rotors at $12000 \mathrm{r} / \mathrm{min}$. As shown in the figures, the maximum stresses indicated by "Max" of the three rotors on the stress plot are at the ribs and their values are well below the yield strength of M270-35A (450 MPa). From this it follows that the ribs are the most critical part to ensure the mechanical strength of the 
rotors. Since less lamination is used per pole in the rotor 'Type B', the maximum stress at the rib is smaller than that of the other two rotors. Conversely the proposed rotor with extended bridges 'Type $C^{\prime}$ has the highest von-Mises stress at the rib albeit its value is still safely below the steel's yield strength by a safe margin.

Fig. 10 shows the tensile stresses of the magnets in the three rotors at $12000 \mathrm{r} / \mathrm{min}$. It can be seen that the maximum tensile stress on the magnets of rotor 'Type $C^{\prime}$ is higher due to the inhomogeneous deformation of the lamination, which is almost double that of rotor 'Type A'. Nonetheless, the maximum mechanical strength of the magnets in the proposed rotor 'Type $C^{\prime}$ does not exceed the tensile strength of N38UH, by an acceptable safety margin.

Table 6 Material properties

\begin{tabular}{ccc}
\hline \hline Parameters & M270-35A & N38UH \\
\hline Mass density $\left(\mathrm{kg} / \mathrm{m}^{3}\right)$ & 7650 & 7500 \\
Young's modulus $(\mathrm{GPa})$ & 200 & 150 \\
Poisson's ratio & 0.3 & 0.24 \\
Yield strength $(\mathrm{MPa})$ & 450 & 800 \\
Tensile strength $(\mathrm{MPa})$ & 565 & 80 \\
\hline \hline
\end{tabular}

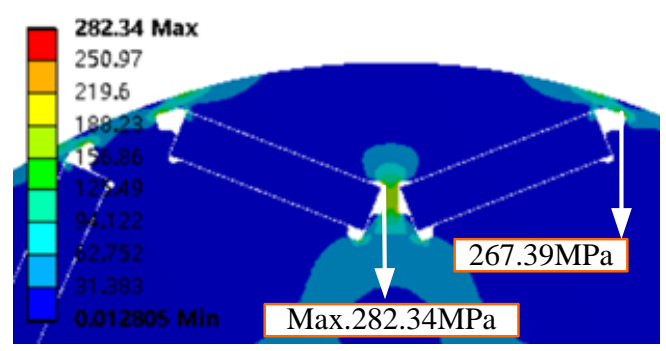

(a)

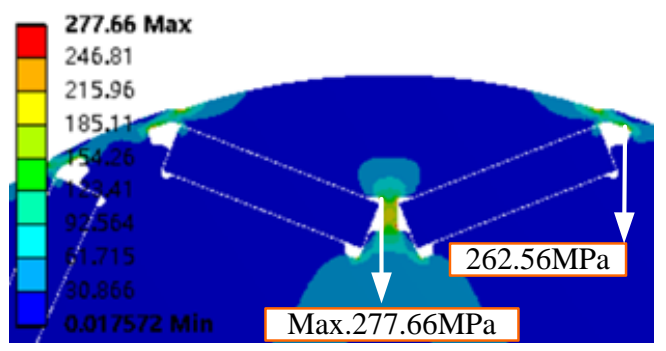

(b)

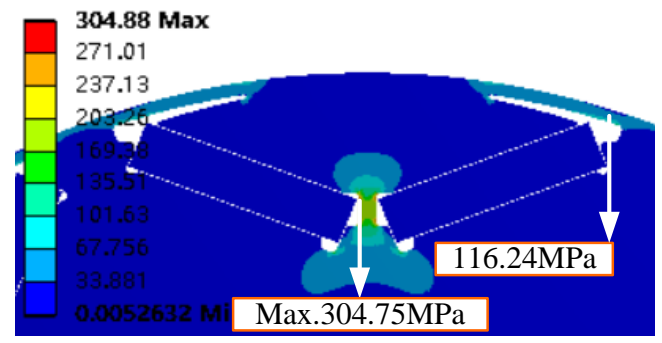

(c)

Fig. 9. Distribution of von-Mises stress of three rotors at 12000 r/min. (a) Type A. (b)Type B. (c)Type C

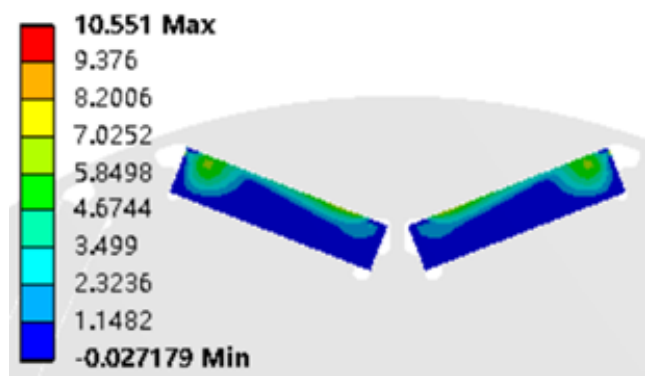

(a)

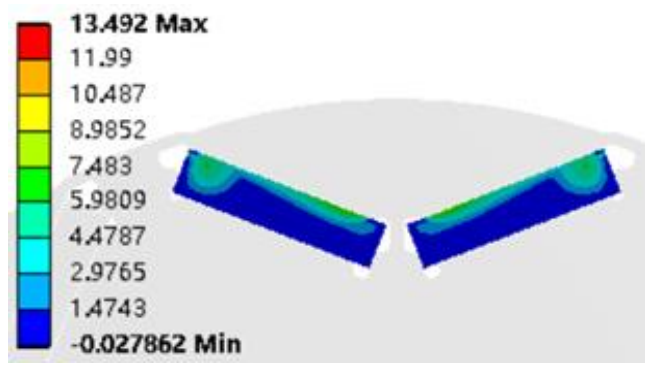

(b)

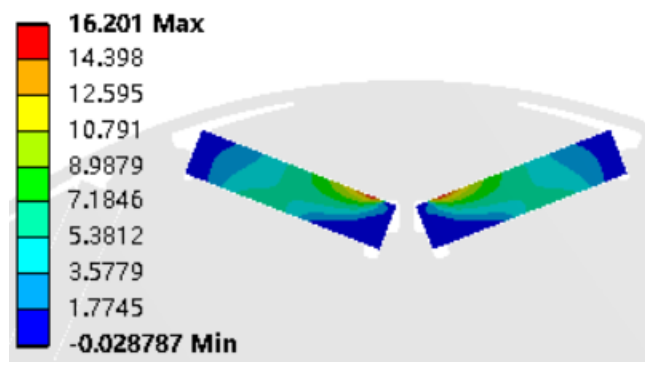

(c)

Fig.10. Tensile stresses of the magnets in the three rotors at 12000 r/min. (a) Type A. (b)Type B. (c)Type C.

\section{Experimental verification}

From the previous sections and foregoing analysis it has been shown that the IPMSM with conventional rotor 'Type $\mathrm{A}^{\prime}$ has the highest cogging torque and torque ripple together with the worst noise and vibration behavior which can be obtained indirectly by calculating the radial force. On the other hand, the IPMSM with the proposed rotor configuration has the lowest air-gap flux density THD, cogging torque, torque ripple and radial force, without resorting to mechanically uneven airgaps and their associated increased airgap friction losses. Taking into account all the considerations discussed in this paper, the

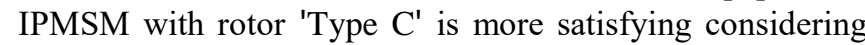
comprehensive system-level considerations and it is selected as the machine to prototype and test. The prototype of $\mathrm{V}$-shape IPMSM with rotor 'Type $\mathrm{C}^{\text {' is manufactured as }}$ shown in Fig. 11. 


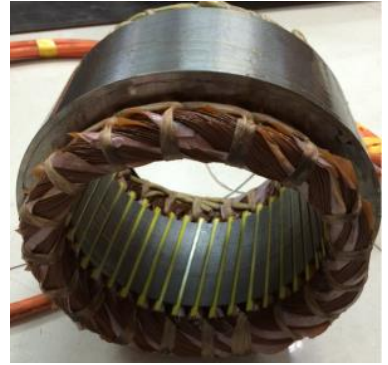

(a)

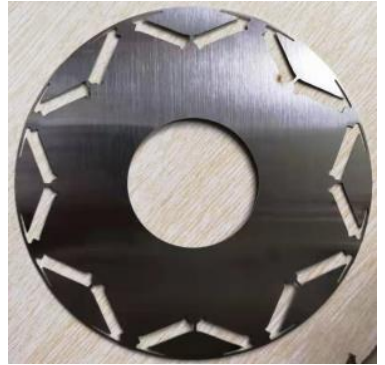

(b)

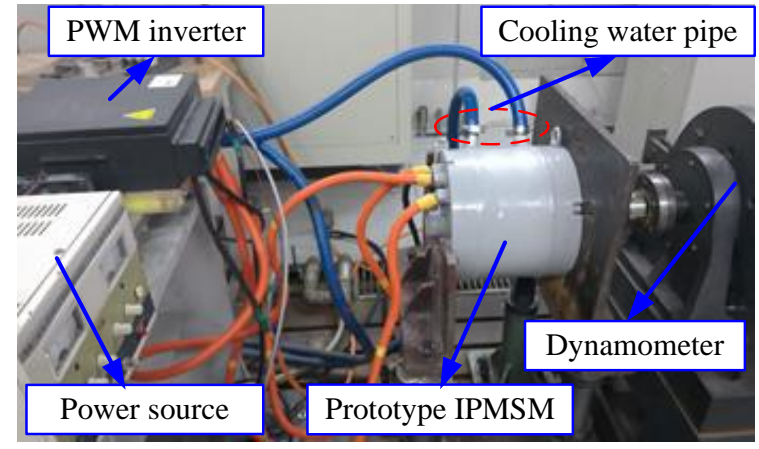

(c)

Fig.11. Prototype and experimental setup. (a) Stator. (b) rotor. (c) experimental setup

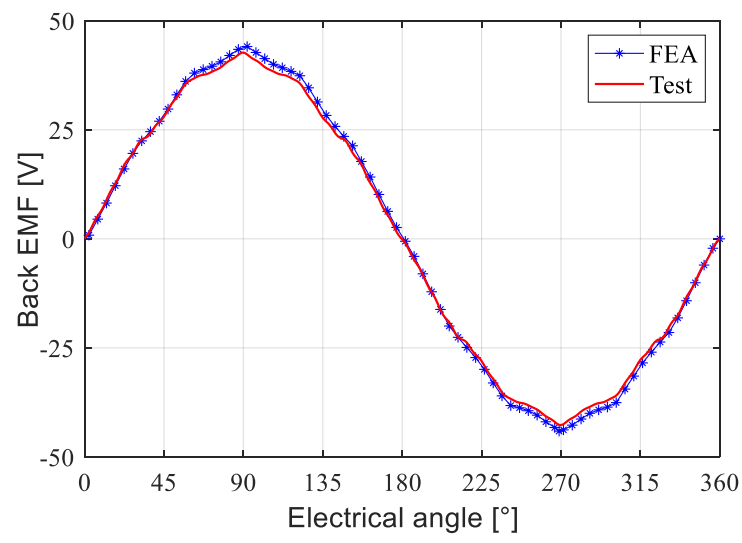

Fig. 12 Comparison result of back EMF at $1250 \mathrm{rpm}$.

The comparison results of phase back-EMF between simulation and experiment are shown in Fig. 12. It can be seen that the measured and calculated phase back-EMF waveforms are in good agreement.

Fig. 13 shows the torque waveforms of the FEA and experimental results at the rated condition under the MTPA control. The torque waveform of the prototype calculated by FEA matches that obtained by the experiment with a small discrepancy, of less than $3 \%$. The torque ripple is lower than $20 \%$, which experimentally validates the foregoing conclusion that the rotor 'Type $\mathrm{C}$ ' is an appropriate structure to reduce the torque ripple. In order to make a more comprehensive evaluation of the prototype, the curves of the maximum torque and the corresponding power and efficiency versus speed are also measured as shown in Fig. 14. The V-shape IPMSM with rotor 'Type $\mathrm{C}^{\prime}$ meets the design specifications listed in Table 1 . Therefore, it is concluded and verified that 'Type $\mathrm{C}^{\prime}$ is a strong candidate rotor structure for IPMSMs used in EVs with good torque characteristics.

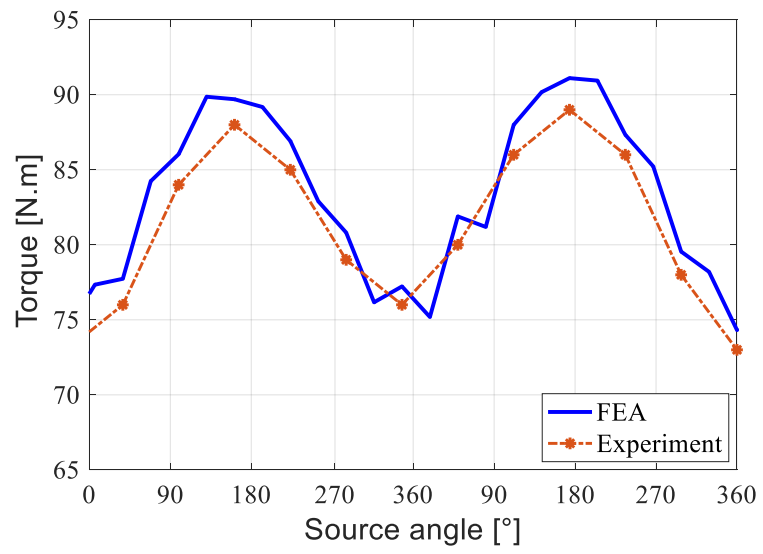

Fig. 13 Torque waveforms of the FEA and experimental result at the rated state (MTPA).

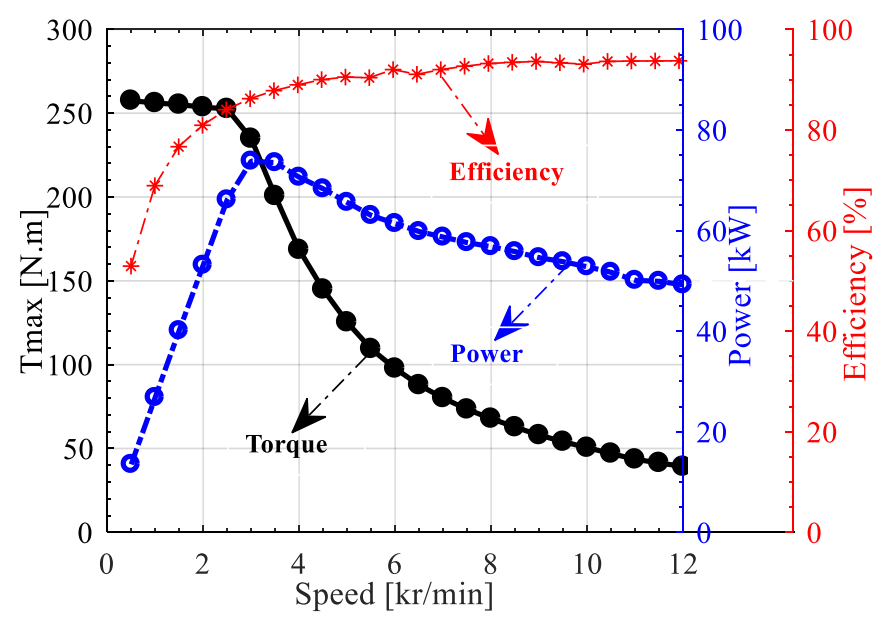

Fig. 14 Maximum torques, powers and efficiencies at different speeds.

\section{Conclusion}

In this paper an improved configuration for V-shaped IPMSM with inward-extended bridges is proposed, analysed and compared to both the classic V-shape rotor configuration as well as the previously-published rotor concept with uneven airgap. It has been shown that the elongated bridge has the effect of making the airgap flux density more sinusoidal and through the analysis and experimentation its main merits of reducing the cogging torque, radial force and torque ripple without sacrificing the average output torque, the maximum torque and the efficiencies demonstrated.

From the authors' experience, for EV traction motors to meet performance and cost targets, there is an increasing recent trend to design for higher rotational speeds as well as use direct oil-spray cooling on the windings [27] with some resulting oil penetration in the airgap. Both these factors contribute to significant increases in airgap mechanical losses, especially if the airgap is non-uniform. The presented rotor topology of this paper melds well with the aforesaid recent trends, and can thus be well-suited for such applications where the torque quality needs to be maximized 
while mitigating the airgap friction losses.

\section{Reference}

[1] Chan, C. C.: 'The state of the art of electric, hybrid and fuel cell vehicles', Proc. IEEE, April 2007, 95, (4), pp. $704-$ 718

[2] Zhu, Z. Q., Howe, D.: 'Electrical machines and drives for EV electric, hybrid and fuel cell vehicles', Proc. IEEE, April 2007, 95, (4), pp. 746-765

[3] Liu, X. D., Chen, H., Zhao, J., et al.: 'Research on the performances and parameters of interior PMSM used for electric vehicles', IEEE Trans. Ind. Electron., 2016, 63, (6), pp. 3533-3545

[4] Zhang, Y., Cao, W. P., Sean, M., et al.: 'Design and flux-weakening control of an interior permanent magnet synchronous motor for electric vehicles', IEEE Trans. Appl. Super., 2016, 26, (7), pp. 1-6

[5] Park, M. R., Kim, H. J., Choi, Y.Y., et al.:

'Characteristics of IPMSM according to rotor design considering nonlinearity of permanent magnet', IEEE Trans. Magn., 2016, 52, (3), pp. 1-4

[6] Kim, K. C., Kim, K., Kim, H. J., et al.: 'Demagnetization analysis of permanent magnets according to rotor types of interior permanent magnet synchronous motor', IEEE Trans. Magn., 2009, 45, (6), pp. 2799-2802

[7] Jung, Y. H., Lim, M. S., Yoon, M. H., et al.: 'Torque ripple reduction of IPMSM applying asymmetric rotor shape under certain load condition', IEEE Trans. Energy Convers., 2018, 33, (1), pp. 333-340

[8] Beccue, P., Neely, J., Pekarek, S., et al.: 'Measurement and control of torque ripple-induced frame torsional vibration in a surface mount permanent magnet machine', IEEE Trans. Power Electron., 2005, 20, (1), pp. 182-191

[9] Chu, W. Q., Zhu, Z. Q.: 'Investigation of torque ripples in permanent magnet synchronous machines with skewing', IEEE Trans. Magn., 2013, 49, (3), pp. 1211-1220

[10] Ge, X., Zhu, Z. Q., Kemp, G., et al.: 'Optimal step-skew methods for cogging torque reduction accounting for three dimensional effect of interior permanent magnet machines', IEEE Trans. Energy Convers., 2017, 32, (1), pp. 222-232 [11] Lee, C., Seol, H. S., Lee, J. Y., et al.: 'Optimization of vibration noise characteristics of skewed permanent brushless direct current motor', IEEE Trans. Magn., 2017, 53, (11), pp. 1-5

[12] Islam, R., Husain, I., Fardoun, A., et al.:

'Permanent-magnet synchronous motor magnet designs with skewing for torque ripple and cogging torque reduction', IEEE Trans. Ind. Appl., 2009, 45, (1), pp. 152-160 [13] Zhao, W. L., Lipo, T. A., Kwon, B. I., 'Torque Pulsation minimization in spoke-type interior permanent magnet motors with skewing ans sinusoidal permanent magnet configurations', IEEE Trans. Magn., 2015, 51, (11), pp. 1-4

[14] Ren, W., Xu, Q., Li, Q.: 'Asymmetrical Y-shape rotor configuration of an interior permanent magnet machine for improving torque characteristics', IEEE Trans. Magn., 2015, 51, (11), pp. 1-4

[15] Ren, W., Xu, Q., Li, Q., et al.: 'Reduction of cogging torque and torque ripple in interior PM machines with asymmetrical V-type rotor design', IEEE Trans. Magn., 2016, 52, (7), pp. 1-4

[16] Hwang, K. Y., Rhee, S. B., Yang, B. Y., et al.: 'Rotor pole design in spoke-type brushless DC motor by response surface method', IEEE Trans. Magn., 2007, 43, (4), pp. 1833-1836

[17] Zhou, Y., Li, H., Meng, G., et al.: 'Analytical calculation of magnetic field and cogging torque in surface-mounted permanent-magnet machines accounting for any eccentric rotor shape', IEEE Trans. Ind. Electron., 2015, 62, (6), pp. 3438-3447

[18] Kwon, Y. C., Sul, S. K., Baloch, N. A., et al.: 'Design modeling and control of an IPMSM with an asymmetric rotor and search coils for absolute position sensorless drive', IEEE Trans. Ind. Appl., 2016, 52, (5), pp. 3839-3850

[19] Zhu, S. S., Hu, Y. H., Liu, C., et al.: 'Iron loss and efficiency analysis of interior PM machines for electric vehicle applications', IEEE Trans. Ind. Electron., 2018, 65, (1), pp. 114-124

[20] Hu, Y. H., Zhu ,S. S., Liu, C., et al.: 'Electromagnetic performance analysis of interior PM machines for electric vehicle applications', IEEE Trans. Energy Convers., 2018, 33, (1), pp. 199-208

[21] Mukundan, S., Dhulipati, H., Lai, C. Y., et al.: 'Design and optimization of traction IPMSM with asymmetrical damper bars for integrated charging capability using evolutionary algorithm', IEEE Trans. Energy Convers., 2018, 33, (4), pp. 2060-2069

[22] Valente, G., Gerada, D., Degano, M., Gerada, C., Foulsham, J., and Beeby, D.: "Optimized sizing of IPM machines for automotive traction application," 2019 IEEE International Electric Machines \& Drives Conference (IEMDC), San Diego, CA, USA, 2019, pp. 970-975. [23] Park, S., Kim, W., Kim, S. I.: 'A numerical prediction model for vibration and noise of axial flux motors', IEEE Trans. Ind. Electron., 2014, 61, (10), pp. 5757-5762 [24] Lin, F., Zuo, S. G., Deng, W., et al.: 'Modeling and analysis of electromagnetic force, vibration and noise in permanent magnet synchronous motor considering current harmonics', IEEE Trans. Ind. Electron., 2016, 63, (12), pp. 7455-7466

[25] Lin, C., Wang, S., Moallem, M., et al: 'Analysis of vibration in permanent magnet synchronous machines due to variable speed drives', IEEE Trans. Energy Convers., 2017, 32, (2), pp. 582-590

[26] Islam, R., Husain, I.: 'Analytical model for predicting noise and vibration in permanent-magnet synchronous motors', IEEE Trans. Ind. Appl., 2010, 46, (6), pp. 23462354

[27] Liu, C.,Xu, Z. Y., Gerada, D., et al., 'Experimental investigation on Oil spray cooling with Hairpin windings ', IEEE Trans. Ind. Electron., 2020, 67, (9), pp. 7343-7353 